
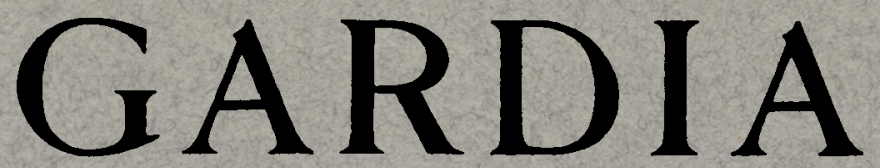

A Journal of Agricultural Science Published by the California Agricultural Experiment Station

\title{
THE PENETRATION OF \\ INSECTICIDAL OILS \\ INTO POROUS SOLIDS
}

W. M. HOSKINS 


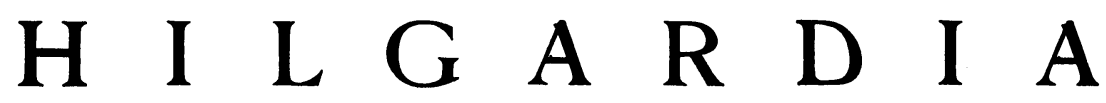

A Journal of Agricultural Science Published by

the California Agricultural Experiment Station

VoL. 8

NOVEMBER, 1933

No. 2

\section{THE PENETRATION OF INSECTICIDAL OILS INTO POROUS SOLIDS ${ }^{1}$}

\author{
W. M. HOSKINS ${ }^{2}$
}

\section{INTRODUCTION}

Many insects and other arthropod pests of economic importance hibernate during the cold season in cracks and cavities in the bark of trees and bushes. Since this occurs when the plants are in a dormant condition and therefore less subject to injury from insecticides, attention has long been directed to the possibility of applying toxic materials to the bark for the control of such pests while they are concentrated in a relatively small area and unable to escape. An example is afforded by the Pacific red spider, Tetranychus pacificus McG., so destructive to grapes in the San Joaquin Valley, which hibernates beneath the loose outside layers of bark on the stumps of grapevines.

The range of available insecticides for such use is very wide. However, solids either as water suspensions or as dusts have little chance of getting far enough into the bark. Fumigants are at a disadvantage for two reasons; first, their volatility is low during cold weather; and secondly, the respiratory activity of hibernating insects is very low (Bodine, 1923). This practically limits the choice to contact insecticides such as aqueous solutions of lime-sulfur, nicotine, etc.; coal-tar products, either straight or in water solution; and mineral or plant oils, either straight or in water emulsions. By adding other toxic materials which are soluble in one or another of the substances just mentioned a very large number of products of possible insecticidal value can be made.

Aside from the question of true toxicity of a given product to a particular insect, the practical effectiveness depends upon whether enough of the material penetrates through the bark to the places where the in-

1 Received for publication March 25, 1933.

2 Assistant Professor of Entomology. 
sects are hibernating. In case a web or other protective covering is present this also must be penetrated. The bark of any particular plant is not a homogeneous material but consists of a number of layers, the outer ones being corky and often adhering but loosely to the underlying layers. In the case of grapevine bark the outer layer is wet readily by water and by oils but the successive inner layers are wet by water with increasing difficulty, so that it is practically impossible for water to penetrate through the bark to the cambium layer. Oils wet all layers but penetration into the inner bark is considerably slower than into the outer bark.

The spread of either water or oil through any kind of bark is a very irregular process because small openings serve as capillary leads and narrow connecting bands between loosely adhering pieces slow down the spread very greatly. In view of these difficulties it seemed better to make the preliminary studies of the penetration of insecticidal oils with porous materials of uniform and duplicable nature. A grade of paper known as California bond (hereafter called "typewriter paper") and a deadening felt $1 / 16$ inch thick were used. These afforded, respectively, the condition of spreading through very thin, dense media and through thick, porous media. Before describing the experimental procedure it will be helpful to review briefly the process of penetration through a medium containing minute openings and cavities.

\section{FACTORS CONCERNED IN CAPILLARY FLOW}

When a capillary tube, open at both ends, is connected with a liquid at a distance below the surface, the liquid will enter the capillary under the influence of two forces, one gravitational and the other interfacial. The first is readily measured in terms of the hydrostatic head existing at any given point, e.g., in figure $1 A$, at point $a$ the force due to gravity is measured by the height $h$ multiplied by the density of the liquid. This is usually expressed in terms of force per unit area, which is pressure, and a wide variety of terms are in use such as dynes per square centimeter, millimeters of mercury, atmospheres, etc. This force may be either positive or negative as shown in figure $1 A$ at point $b$ where a negative force is exerted equal to the height $h^{\prime}$ multiplied by the density of the liquid.

The interfacial force, often called the capillary force, is more diffcult to define. It is the result of a change in energy that occurs when the solid-air interface of the bore of the tube is replaced by the solidliquid interface as the liquid advances into the capillary tube. At any 
interface (i.e., boundary between two different kinds of matter), the balance between the forces of attraction and of repulsion which exists within the material on either side of the interface is no longer exact. This lack of balance results in a display of energy in some form. A very familiar example is the interface between water and air, ordinarily, but somewhat incorrectly, called the water surface. The lack of balance in this interface gives rise to the property called the surface tension of water, which has a definite magnitude at each temperature and can be measured by a variety of methods (Rideal, 1930, pages 1-25; National
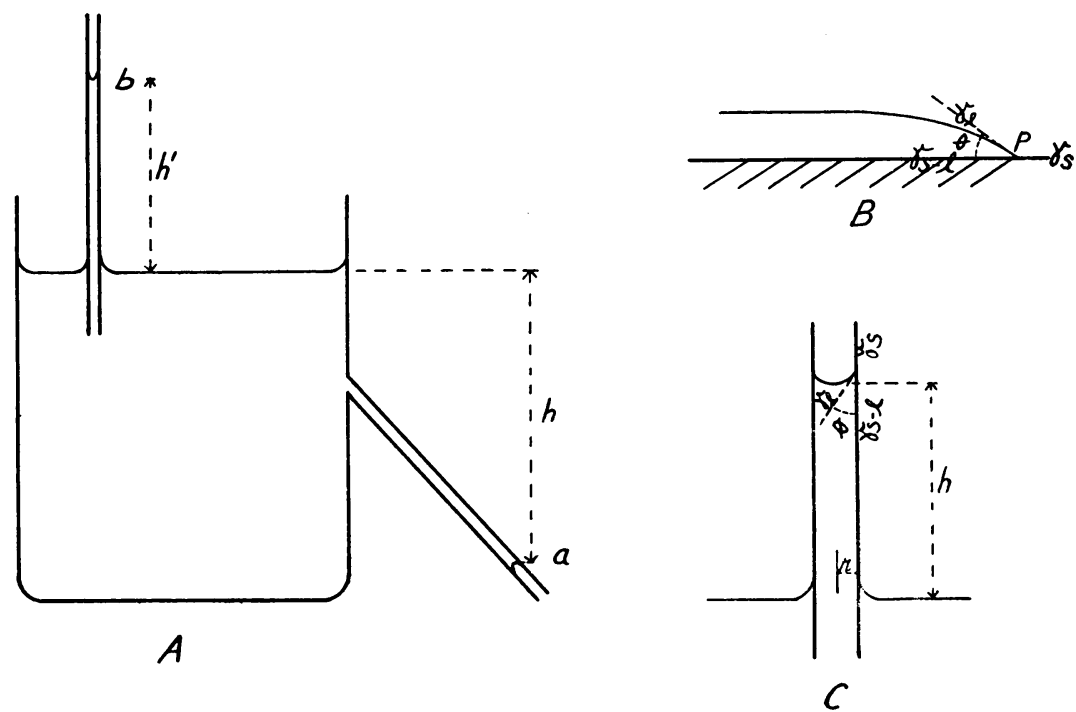

Fig. 1. $A$, The entrance of a liquid into a tube: $a$, aided by gravity; $b$, against gravity. $B$, The equilibrium condition of a liquid spreading on a solid (vertical section). $C$, The equilibrium condition of a liquid rising into a tube.

Research Council, 1928, page 435). Similarly, at any kind of interface an interfacial tension exists. Whenever a solid is concerned the interfacial tension cannot be measured by any method so far devised, and sinee in these cases the physical phenomena by which interfacial tensions are usually measured cannot be perceived, the more general term "interfacial energy" is used.

In the case of a liquid entering a capillary tube, it is obvious that the process results in the replacement of the original solid-air interface by a solid-liquid interface. If the original energy per unit area of interface is greater than the final energy, the difference will be available for drawing liquid into the capillary tube. While neither the initial nor final interfacial energy can be measured, the difference between them can be 
readily determined. If a drop of a liquid is placed on a flat, horizontal surface of a solid the liquid will ultimately assume an equilibrium position, and if it wets the solid the final layer will be too thin for gravity to have an appreciable effect. This equilibrium position is characterized by a definite angle of contact, $\theta$, as shown in figure $1 B$, which represents a vertical cross section through a drop of liquid on a solid. At point $P$ three different interfaces meet. The interfacial energies are those of the solid-air interface $\left(\gamma_{\mathrm{s}}\right)$, the liquid-air interface $\left(\gamma_{1}\right)$, and the solid-liquid interface $\left(\gamma_{\mathrm{sl}}\right)$. Since equilibrium in spreading has been reached, the energies on opposite sides of point $P$ must be equal. Since only the horizontal component of $\gamma_{1}$ is effective in the plane of the surface of the solid, the equation of equilibrium is :

$$
\gamma_{\mathrm{s}}=\gamma_{\mathrm{s} 1}+\gamma_{1} \cos \theta
$$

Hence the change in interfacial energy that occurs when a solid-air interface is replaced by a solid-liquid interface may be expressed:

$$
\Delta \gamma=\gamma_{\mathrm{s}}-\gamma_{\mathrm{s} 1}=\gamma_{1} \cdot \cos \theta
$$

The change in energy per unit area of interface can therefore be determined from a knowledge of the surface tension of the liquid and the angle of contact.

To apply this reasoning to calculation of capillary force it is necessary to consider a capillary tube in which a liquid of density $d$ has risen to equilibrium as represented in figure $1 C$. All terms have the same meaning as in the previous figure, and as before: $\Delta \gamma=\gamma_{\mathrm{s}}-\gamma_{\mathrm{s} 1}=\gamma_{1}$ $\cos \theta$. The total energy available per unit length of the capillary tube is then $2 \pi r \gamma_{1} \cos \theta$. This energy is holding up a column of liquid with a cross-sectional area of $\pi r^{2}$. Hence the energy per unit cross-sectional area is :

$$
\epsilon=\frac{2 \pi r \gamma_{1} \cos \theta}{\pi r^{2}}=\frac{2 \gamma_{1} \cos \theta}{r}
$$

III

which has been called the capillary pressure, $P_{\mathrm{c}}$ (Washburn, 1921), and is the interfacial force previously mentioned which causes a liquid to enter a tube.

The relative importance of the gravitational and interfacial forces in influencing the entry of a liquid into a capillary tube may be illustrated by an example. Consider a hypothetical liquid with a density of 0.86 grams per cc and a surface tension of 28 dynes per cm, whose angle of contact on a certain solid is $5^{\circ}$. The gravitational force, $P_{\mathrm{g}}$, in dynes for various heights in the tube above the liquid surface as in figure 1 is given by the product $h d g$ in which $g$ is the acceleration due to gravity (980 cm per sec. per sec.) and the other terms are as defined before. The inter- 
facial force, $P_{\mathrm{c}}$, in dynes per square centimeter, is given by the expression $\frac{2 \gamma_{1} \cos \theta}{r}$. This is worked out, for various radii of the tube in table 1 .

It is apparent that for small capillaries and small hydrostatic heights, which will be the conditions prevailing at the beginning of movement through capillary tubes under any ordinary conditions, the effect of gravity is negligible.

TABLE 1

Relative Magnitude of Gravitational and INTERFACIAL FORCES

\begin{tabular}{|c|c|c|c|}
\hline \multicolumn{2}{|c|}{ Gravitational force } & \multicolumn{2}{|c|}{ Interfacial force } \\
\hline$h$, in $\mathrm{cm}$ & $\begin{array}{c}P_{g}, \text { in dynes } \\
\text { per square } \\
\text { cm }\end{array}$ & $r$, in $\mathrm{cm}$ & $\begin{array}{c}P_{c} \text {, in dynes } \\
\text { per square } \\
\text { cm }\end{array}$ \\
\hline 1 & 2 & 3 & 4 \\
\hline 1 & 842.8 & 0.1 & 557.7 \\
\hline 10 & 8,428 & 0.01 & $5,577.6$ \\
\hline 100 & 84,280 . & 0.001 & 55,776 \\
\hline$\ldots$ & ……........... & 0.0001 & 557,760 . \\
\hline
\end{tabular}

The expression derived for the capillary pressure which causes a liquid to flow into a tube does not tell anything about the rate at which the head of the liquid column will move. In order to calculate this, certain assumptions must be made concerning the manner in which flow takes place. Poiseuille $(1842,1846)$ assumed that straight-line flow occurs, as distinguished from turbulent or rolling motion (Martin, 1928), that no slipping occurs at the boundary wall of the tube, and that the friction is proportional to the slip of each infinitesimally thin layer on the layer next to it. In the present case the law of Poiseuille, subject to the assumptions above, states that the volume of liquid passing a given point in a tube of fixed radius in unit time is directly proportional to the product of the pressure under which it is flowing and the fourth power of the radius of the tube and inversely proportional to the product of the viscosity of the liquid and the length of the liquid column in the tube. In symbols it may be written:

$$
\nabla=\frac{\pi r^{4} P \Delta t}{8 \eta l}
$$

in which $V$ is the volume of liquid, $P$ is the total effective pressure, $r$ is the radius of the tube, $\Delta t$ is the duration of flow considered, $\eta$ is the viscosity of the liquid, and $l$ is the length of tube filled. Since in a tube of radius $r$ a volume $V$ would occupy a length $\frac{V}{\pi r^{2}}=\Delta l$, in which $\Delta l$ is the 
distance moved in the time $\Delta t$, the above expression may be rewritten:

$$
\Delta l=\frac{r^{2} P \cdot \Delta t}{8 \eta l}
$$

which gives the distance that the advancing front of the column will move in the time $\Delta t$. Substituting the expression found above for the capillary pressure and neglecting the hydrostatic pressure, the following equation is obtained:

$$
\Delta l=\frac{2 \gamma_{1} \cos \theta}{r} \cdot \frac{r^{2} \Delta t}{8 \eta l}=\frac{\gamma_{1} \cos \theta r \Delta t}{4 \eta l}
$$

Hence the linear rate of flow,

$$
f=\frac{\Delta l}{\Delta t}=\frac{\gamma_{1} \cos \theta r}{4 \eta l}
$$

Since the angle of contact is zero or nearly so for most liquids on most solids this may be rewritten in its approximate form for very small values of $\theta$, as :

$$
\text { linear rate of flow, } f=\frac{\Delta l}{\Delta t}=\frac{\gamma_{1} r}{4 \eta l}
$$

VIII

In order to change this rate equation into one involving total distance moved through, it is necessary to sum up the motions at every instant from the beginning to any time in question, i.e., to integrate the last equation above which may be written in differential form:

Integrating,

$$
l \mathrm{~d} l=\frac{\gamma_{1} r \mathrm{~d} t}{4 \eta}
$$

IX

$$
\frac{l^{2}}{2}=\frac{\gamma_{1} r t}{4 \eta} \text { or } l=\left(\frac{\gamma_{1} r t}{2 \eta}\right)^{1 / 2}
$$

$\mathrm{X}$

The argument developed above may be applied immediately to flow through a porous medium by considering that it contains many capillaries of various sizes, lengths and arrangements, in each of which the liquid flows in accordance with the equations given above.

The term $r$ becomes then a weighted average radius, or to be more precise it is the fourth root of the average fourth power of the radii (see equation IV), as emphasized by Stamm (1928). It will be noted that the distances to which two liquids will penetrate a given kind of porous solid in a given time vary directly as the square root of the ratio of the surface tensions and inversely as the square root of the ratio of the viscosities. For a given liquid in a given solid the equation for distance penetrated may be written, $l=K_{1} t^{1 / 2}$. This is a particular form of the general expression, $l=K_{2} t^{1 / n}$, which has been found to hold for the movement of many kinds of fluids through a variety of porous solids. In 
these equations $K_{1}, K_{2}$, and $n$ are constants, and since $K_{1}$ and $K_{2}$ are functions of both the liquid and the solid concerned these equations are of little use in classifying either kind of material.

Bell and Cameron (1906) investigated the flow of water and of aqueous solutions of several inorganic salts and dyes through filter paper, blotting paper, and soils. They found $n$ of the above equation to be very close to 2 in all cases, whereas $K_{2}$ varied widely, as might be expected. Among recent studies is the work of Stamm $(1928,1932)$ who used rates of flow of liquids through thick wooden membranes in determining the number and nature of the pores in several soft woods such as red cedar and spruce. Bartell and Osterhof (1928) used the same method in a careful study of the structure of compressed carbon and silica. Ginsburg (1931) found the rate of penetration of petroleum oils into leaf tissue and into the bark of apple twigs to vary inversely as the viscosity.

As stated in the foregoing deduction, the equations derived above for the flow of liquids through porous solids hold only when spreading is far from equilibrium, and fail if it proceeds upward to a considerable distance. If this occurs the gravitational force will become significant and may be important not only by slowing down the rate of spread but also by determining the total distance the liquid will penetrate. A number of other factors may intervene to make the rate of spread less than that calculated by the equations. Thus, if oxidation of the liquid occurs, the viscosity will ordinarily increase, with consequent slowing-down of the rate of spread. Also, if the solid contains substances soluble in the liquid the viscosity may increase, e.g., the resins present in bark have this effect on light oils. If the liquid is a solution, preferential adsorption on the walls of the capillaries may occur with resultant changes in surface tension and viscosity and more or less separation of the components of the solution.

In the foregoing discussion a limit on how far a liquid will move through a capillary tube or porous solid dipping into it has been mentioned for only one condition, i.e., when the liquid rises until the capillary pressure is balanced by the hydrostatic pressure due to gravity. Theoretically there is no limit to how far movement will proceed through a tube or porous solid in a horizontal or downward direction provided there is an unlimited supply of liquid. Of course, if for any reason the viscosity increases sufficiently the motion will become infinitesimally small and if a gel is formed no motion will occur. Evaporation of a liquid from a porous solid may become equal to the rate of flow, especially if the surrounding atmosphere is moving.

The very important question of how far a given quantity of a liquid will spread through a porous solid is connected with the changes in 
interfacial energy previously mentioned. If no adsorption, evaporation, or change in viscosity occurs, it is obvious that flow will continue into the various-sized spaces in accordance with theory until all the liquid has entered the solid. A second phase will then ensue during which smaller capillaries at the limit of flow will fill at the expense of larger ones previously filled. To make clear how this process is possible, it is necessary to notice once more the energy changes involved when liquid enters or leaves a capillary tube. The filling of a tube is shown in figure
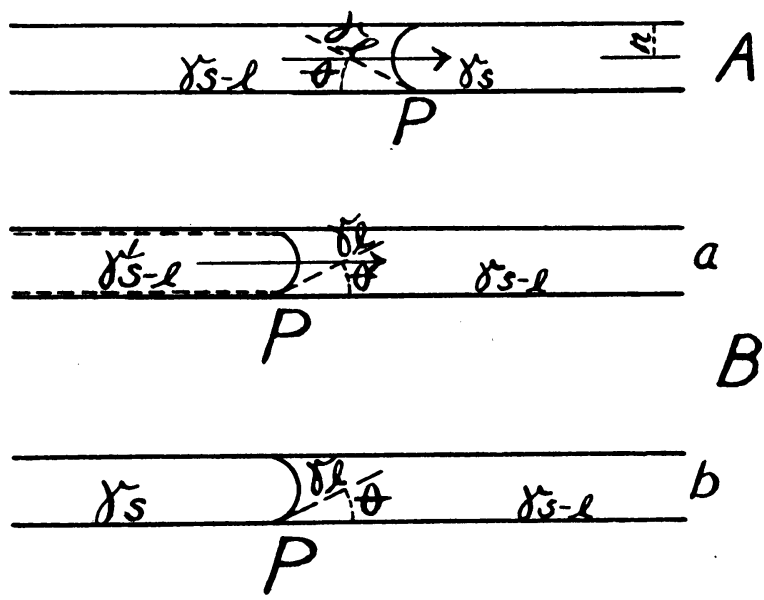

Fig. 2. $A$, Entrance of a liquid into a tube. $B$, The emptying of a tube: $a$, illustrating the thin film left on the walls when a liquid is withdrawn from a tube; $b$, final condition after the film on the walls is removed.

$2 A$ for which, as deduced before (equation II), the change in energy per unit area of interface is $\Delta \gamma=\gamma_{\mathrm{s}}-\gamma_{\mathrm{s} 1}=\gamma_{1} \cos \theta$ and the capillary pressure is $\frac{2 \gamma_{1}}{r}$ when the angle of contact is zero. Figure $2 B$ illustrates the emptying of a capillary tube. Emptying is not simply the opposite of filling, for a film of liquid adsorbed on the interior surface of the tube is left behind. The process of completely emptying a capillary tube may be thought of as occurring in two steps : (1) removal of all liquid except a thin layer on the wall (fig. $2 B, a$ ); and (2) cleaning this adsorbed layer from the wall (fig. $2 B, b$ ). The energy changes in these two steps may be formulated as before (remembering that the signs will be opposite because the process is reversed from that of filling a tube ) :- $-\Delta \gamma^{\prime}=$ $\gamma_{s 1}^{\prime}-\gamma_{s 1}$ in which $-\Delta \gamma^{\prime}$ is the energy change per unit of interface for step $1, \gamma^{\prime}{ }_{s 1}$ is the energy of the interface between air and the solid plus its adsorbed layer of liquid, and $\gamma_{\mathrm{s} 1}$ is the energy of the solid-liquid in- 
terface. And $-\Delta \gamma^{\prime \prime}=\gamma_{\mathrm{s}}-\gamma^{\prime}{ }_{\mathrm{s}}$, in which $-\Delta \gamma^{\prime \prime}$ is the energy change per unit of interface for step 2, $\gamma_{\mathrm{s}}$ is the energy of the solid-air interface, and $\gamma^{\prime}{ }_{s 1}$ is as before. Adding the energy changes for the two steps :

$$
-\left(\Delta \gamma^{\prime}+\Delta \gamma^{\prime \prime}\right)=\gamma_{s 1}^{\prime}-\gamma_{s 1}+\gamma_{s}-\gamma_{s 1}^{\prime}=\gamma_{s}-\gamma_{s 1}
$$

$\mathrm{XI}$

which equals the energy change involved in filling the capillary tube as deduced previously (equation II). Since the energy evolved in filling a capillary tube can thus be shown to be equal to the sum of the energies consumed in emptying and cleaning the same capillary or one of equal radius, it follows that the energy required to empty a tube of all the liquid in it except the layer next to the wall is less than the energy liberated in filling another tube of equal or smaller radius, and therefore a liquid will flow from larger capillaries into smaller ones until only a thin layer of adsorbed liquid is left on the walls of the larger ones. The final condition in a porous solid containing all sizes of tubes and cavities will be for the liquid to fill completely only the tiniest capillaries and be spread over the interior surface of all larger spaces in a layer whose thickness will depend upon the properties of both the solid and the liquid.

\section{SUBSTANCES STUDIED AND MEASUREMENT OF SURFACE TENSION, DENSITY, VISCOSITY, VOLATILITY, AND UNSULFONATABLE RESIDUE}

A wide variety of spray oils was secured, most of which were the stock oils from which commercial emulsions are made. They varied considerably in the properties of unsulfonatable residue, surface tension, viscosity, and density as shown in table 2 . These oils were secured from the producers in closed containers and were protected from exposure to air and light before use. In addition to the petroleum oils a number of vegetable oils, miscible oils, and chemicals that are not oils at all were also studied. These were all of technical grade since the aim was to obtain data on materials of insecticidal value rather than of high purity. For this reason the data on some of the above-mentioned properties for the materials in the last group are slightly different in a few cases from data given by other workers for pure compounds.

According to the foregoing discussion the surface tension and viscosity of a liquid affect its rate of entry into a porous solid. Reports of determination of these properties under conditions suitable for application to the results of spreading experiments are scarce. In particular, but few determinations of the surface tensions of suitable oils for use in spraying have been made, and viscosities have usually been expressed in 
TABLE 2

Penetrativity and Related Properties of Liquids Studied

\begin{tabular}{|c|c|c|c|c|c|c|c|}
\hline Substance & $\begin{array}{l}\text { Unsul- } \\
\text { fonatable } \\
\text { residue } \\
\text { (U. R.) }\end{array}$ & $\begin{array}{c}\text { Saybolt } \\
\text { viscosity } \\
\text { in seconds } \\
\text { at } 100^{\circ} \mathrm{F}\end{array}$ & $\begin{array}{l}\text { Absolute } \\
\text { viscosity } \\
\text { in poises } \\
\text { at } 25^{\circ} \mathrm{C}\end{array}$ & $\begin{array}{c}\text { Surface } \\
\text { tension } \\
\text { in } \\
\text { dynes } \\
\text { per cm } \\
\text { at } 25^{\circ} \mathrm{C}\end{array}$ & $\begin{array}{l}\text { Density, } \\
\text { in grams } \\
\text { per cc } \\
\text { at } 25^{\circ} \mathrm{C}\end{array}$ & $\begin{array}{l}\text { Pene- } \\
\text { trativity, in } \\
\text { cm per sec. } \\
\text { at } 25^{\circ} \mathrm{C}\end{array}$ & $\begin{array}{c}\text { Actual } \\
\text { pene- } \\
\text { trativity in } \\
\text { typewriter } \\
\text { paper } \\
\text { at } 25^{\circ} \mathrm{C}\end{array}$ \\
\hline 1 & 2 & 3 & 4 & 5 & 6 & $\gamma$ & 8 \\
\hline \multicolumn{8}{|c|}{ Mineral oils } \\
\hline 1 (fly spray).. & 98 & 32 & 0.0125 & 27.0 & 0.796 & 1,080 & 993. \\
\hline 2 (fly spray)... & 90 & 40 & 0.0166 & 27.6 & 0.820 & 832. & 828. \\
\hline 3 (kerosene) & 98 & 42 & 0.0180 & 27.3 & 0.794 & 760. & \\
\hline 4 & 90 & 50 & 0.0220 & 27.7 & 0.821 & 630. & \\
\hline 5 & 90 & 50 & 0.0235 & 29.4 & 0.853 & 626. & \\
\hline 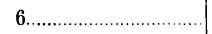 & 99 & 43 & 0.057 & 29.5 & 0.841 & 259 . & \\
\hline 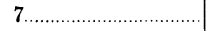 & 89 & 44 & 0.062 & 30.0 & 0.855 & 242 . & \\
\hline $8 \ldots$ & 70 & 44 & 0.064 & 30.5 & 0.878 & 238. & \\
\hline $9 \ldots$ & 90 & 55 & 0.107 & 30.5 & 0.859 & 143. & \\
\hline $10 \ldots \ldots \ldots \ldots \ldots$ & 90 & 52 & 0.107 & 30.8 & 0.859 & 144. & \\
\hline 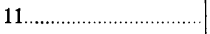 & 90 & 56 & 0.140 & 31.4 & 0.877 & 112 & \\
\hline 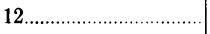 & 92 & 87 & 0.190 & 31.1 & 0.871 & 81.9 & equal \\
\hline $13 \ldots \ldots$ & 99 & 99 & 0.197 & 30.8 & 0.865 & 78.2 & to \\
\hline 14 & 92 & 86 & 0.250 & 31.4 & 0.848 & 62.8 & theoretical \\
\hline $15 \ldots \ldots \ldots \ldots \ldots \ldots \ldots \ldots \ldots \ldots \ldots \ldots \ldots$ & 65 & 75 & 0.259 & 32.4 & 0.908 & 62.6 & \\
\hline $16 \ldots \ldots \ldots \ldots \ldots$ & 60 & 95 & 0.342 & 32.3 & 0.910 & 47.2 & \\
\hline 17 & 70 & 100 & 0.369 & 32.7 & 0.914 & 44.4 & \\
\hline 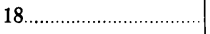 & 65 & 105 & 0.455 & 32.7 & 0.918 & 36.0 & \\
\hline 19 & 70 & 120 & 0.466 & 32.9 & 0.920 & 35.4 & \\
\hline 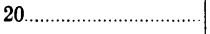 & 70 & 140 & 0.578 & 33.1 & 0.919 & 28.6 & \\
\hline $21 \ldots \ldots \ldots \ldots \ldots \ldots \ldots \ldots \ldots$ & 65 & 200 & 0.941 & 33.2 & 0.918 & 17.7 & \\
\hline $22 \ldots \ldots \ldots \ldots \ldots \ldots \ldots \ldots$ & 59 & 227 & 0.990 & 33.1 & 0.915 & 16.7 & \\
\hline \multicolumn{8}{|c|}{ Miscible oils } \\
\hline 1 . & n........... & ............. & 0.126 & 25.9 & 0.915 & 103.1 & 69.0 \\
\hline 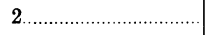 & ............ & ............ & 0.410 & 28.6 & 0.909 & 34.9 & 32.0 \\
\hline 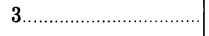 & $\ldots \ldots \ldots \ldots$ & ............. & 0.466 & 32.5 & 0.915 & 34.9 & 15.0 \\
\hline \multicolumn{8}{|c|}{ Plant products } \\
\hline Pine oil 1......................... & ........ & ............. & 0.0175 & 29.6 & 0.897 & 847. & 830. \\
\hline Terpinol........................ & ............. & ............ & 0.0175 & 29.5 & 0.878 & 843. & 648. \\
\hline Turpentine & ............. & $\ldots \ldots \ldots \ldots$ & 0.0180 & 27.9 & 0.847 & 775 . & 664. \\
\hline Pine oil $2 \ldots \ldots \ldots$ & …............ & $\ldots \ldots \ldots \ldots$ & 0.137 & 32.0 & 0.930 & 117. & 95.0 \\
\hline Oleic acid...................... & ............ & - & 0.305 & 33.4 & 0.882 & 54.7 & 33.2 \\
\hline Cottonseed oil............. & $\ldots \ldots \ldots \ldots$ & & 0.559 & 34.2 & 0.910 & 30.6 & 31.0 \\
\hline \multicolumn{8}{|c|}{ Non-oils } \\
\hline Ethyl acetate......... & & ....... & 0.0044 & 25.0 & 0.885 & 2,840 & 1,020 \\
\hline Butyl acetate......... & $\ldots \ldots \ldots \ldots$ & $\ldots \ldots \ldots \ldots$ & 0.0070 & 25.7 & 0.860 & 1,840 & 745. \\
\hline Butanol................... & …......... & ............ & 0.0250 & 25.2 & 0.805 & 504. & 320. \\
\hline o-toluidine..................... & n.......... & ............. & 0.0345 & 41.0 & 0.992 & 594. & 171. \\
\hline Cresol (technical)... & …........... & …........... & 0.109 & 38.5 & 1.028 & 177. & 61.3 \\
\hline 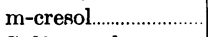 & ............ & ............ & 0.118 & 37.6 & 1.026 & 158. & 67.7 \\
\hline $\begin{array}{l}\text { Sulfonated petro- } \\
\text { leum soap................ }\end{array}$ & ……...... & …........... & 0.780 & 30.6 & 0.924 & 19.6 & 19.4 \\
\hline
\end{tabular}


empirical units such as Saybolt seconds, which are not directly proportional to absolute viscosities. Besides, viscosity determinations have usually been made at elevated temperatures and from the results of such experiments it is impossible to estimate even relative viscosities at ordinary temperatures where spreading ability is of practical interest. This is true because the viscosities of various oils change with temperature at different rates.

In the present work measurements have been made of the surface tensions and absolute viscosities of a considerable number of insecticidal oils and of several related substances. Values for those whose spreading powers have been studied are collected in table 2. All determinations were made in an air bath provided with a mercury regulator for temperature control, and a fan, and armholes through which instruments inside could be reached with minimum disturbance of the temperature. Observations were made through a window in one side. The temperature as indicated by a mercury thermometer never was outside the interval of $25.0^{\circ} \pm 0.1^{\circ} \mathrm{C}$. Since temperature fluctuations in an air bath are rapid, the variation in temperature of the liquids was considerably less than the interval mentioned. All liquids were put into large stoppered test tubes and left in the air bath for at least 2 hours before measurements were made on them.

Surface tensions were determined with a du Noüy Universal Tensiometer which was carefully standardized with weights (du Noüy, 1925) from a calibrated set. The liquid was poured into a 4 -inch crystallizing dish for measurement. At the moment a determination was to be made the fan in the air bath was stopped to prevent motion in the surface of the liquid. An attempt was made to measure a fresh surface, since preliminary experiments showed that upon standing the surface tension decreased, particularly in the case of solutions. Each value in table 2 is the average of several closely agreeing measurements. The correction for the weight of liquid lifted above the surface by the ring was made (for the particular ring used) in accordance with the tables of Harkins and Jordan (1930). The accuracy of this correction is indicated by the fact that the surface tension of doubly distilled water was found to be 72.0 dynes per centimeter at $25.0^{\circ} \mathrm{C}$ (National Research Council, 1928, p. 447).

Determinations of viscosity were made by finding the time required for 2 cubic centimeters of the various liquids to flow through the capillary tube of an Ostwald viscometer. According to the equation previously deduced for capillary flow,

$$
V=\frac{\pi r^{4} P \Delta t}{8 \eta l}=\frac{K P \Delta t}{\eta}
$$


But in the Ostwald instrument the pressure is due solely to the difference in level of the liquid in the two arms and hence is proportional to the density of the liquid. Incorporating this proportionality constant with the constant $K$ above, the equation may be written, $V=K_{1} \frac{d \Delta t}{\eta}$. Since the same volume was used in all cases the time of flow of a number of liquids of known density and viscosity was found and a graph made of $d \Delta t$ versus $\eta$. This would be a straight line if all the assumptions of Poiseuille previously mentioned held exactly. Actually a number of corrections are involved (Bingham and Jackson, 1917). However, these need not be calculated and they only resulted in a very slight curvature in the plot of $d \Delta t$ against $\eta$ in the region of low viscosity. International

TABLE 3

Relation Between Absolute Viscosity of Sugar Solution and Time of Flow Through Ostwald Pipet'te

\begin{tabular}{c|c|c|c}
\hline $\begin{array}{c}\text { Per cent } \\
\text { sucrose }\end{array}$ & $\begin{array}{c}\text { Absolute viscosity } \\
\text { in poises, } \eta^{*}\end{array}$ & $\begin{array}{c}\text { Density in grams } \\
\text { per cc, } d^{*}\end{array}$ & $\begin{array}{c}\text { Time of flow in } \\
\text { seconds, } t\end{array}$ \\
\cline { 2 - 3 } & 0.00894 & 0.9971 & 88.4 \\
20 & 0.01710 & 1.0794 & 155.8 \\
40 & 0.05206 & 1.1744 & 435.1 \\
60 & 0.4402 & 1.2840 & $3,436$. \\
\hline
\end{tabular}

* From Bingham, E. C., and R. F. Jackson. Standard substances for the calibration of viscometers. U. S. Dept. Comm. Bur. Standards Sci. Paper 298: 86-95. 1917.

Critical Tables (National Research Council, 1929) cite the data of Bingham and Jackson (with slight corrections) for the densities and absolute viscosities of water and of a number of sucrose solutions at $25.0^{\circ} \mathrm{C}$. Their directions were followed in preparing the solutions, and the times of flow through the Ostwald viscometer were repeatedly determined. The results are presented in table 3 . All the values in table 3 are for $25.0^{\circ} \mathrm{C}$. Since the absolute viscosity of water at $20.0^{\circ} \mathrm{C}$ is 0.01005 poises ( 1.005 centipoises) the above values and all others derived by using them, when expressed in centipoises, show at once how many times more viscous than water a given liquid is.

Each of the four groups of substances included in table 2 are arranged in the order of increasing viscosity, since this property varies more widely than the other properties listed, and is very influential in determining the rate of penetration into porous solids.

Since the densities of the liquids occur in the equation for calculating viscosity, it was necessary to determine these values. They were found by weighing 50-ce volumes measured at $25.0^{\circ} \mathrm{C}$ and are included in 
table 2. To determine the viscosity of a given liquid from its time of flow through the Ostwald viscometer, the time (in seconds) was multiplied by the density; and from the graph of $d \Delta t$ versus $\eta$ the latter was determined. It is interesting to note that for the mineral oils the three properties, surface tension, viscosity, and density increase together fairly consistently; whereas this does not hold for the other groups. Francis and Bennett (1922) found the same relations for petroleum oils.

The volatility of certain substances was determined by finding the loss in weight when 1 gram of the liquid mixed with 9 grams of a 20-40 mesh sand in a 10-cm flat-bottomed petri dish was kept on a boiling water bath for various intervals. This is the method used by the Division of Chemistry of the California State Department of Agriculture (Elmore, 1931).

The degree of refinement of the mineral oils was found by the method used by the State Department of Agriculture (Elmore, 1931). Not all oils were tested in this laboratory; for some of them were special preparations from the research laboratories of oil companies whose characteristics had been carefully determined there. Since slight variations of the unsulfonatable residue did not enter into this work such analyses were accepted as correct.

\section{MEASUREMENT OF RATES OF SPREADING}

Straight Oils in Paper and $F$ elt.-The experiments on rate of spreading were made by placing a few cubic centimeters of the liquid in a 1 by 8-inch test tube and hanging a strip of the solid (typewriter paper or deadening felt) from the cork in such a manner that its lower end was immersed for a short distance in the liquid, but the strip did not touch the side of the tube at any point. Two short pins stuck at right angles through the end of the strip made this easily possible. A width of $5 / 8$ inch was convenient and was adopted as standard. Since the corks were put in firmly and not removed during the experiment the air remained practically saturated with the vapor of the liquid being studied, and loss by evaporation from the strip as the liquid rose was reduced to a minimum. The height to which the liquid had risen in the strip above the surface of the liquid in the bottom of the upright tube was measured from the outside at convenient intervals without disturbing the arrangement in any way. All experiments were repeated a number of times with close agreement. Averages are used in all calculations.

The data secured are far too voluminous to tabulate, but the behavior of several typical substances is shown in figure 3 . The great differences 
in rate of spread of different oils are illustrated and the effect of the nature of the solid is also shown in the case of a few oils. The equations previously deduced for the rate of flow of a liquid through a porous solid may be tested by the data secured. It will be recalled that the distance penetrated is related to the other factors by equation $\mathrm{X}, l^{2}=\frac{\gamma_{1} r t}{2 \eta}$. Hence, $\frac{2 l^{2} \eta}{\gamma_{1}}=r t$ and upon plotting the left-hand term against the

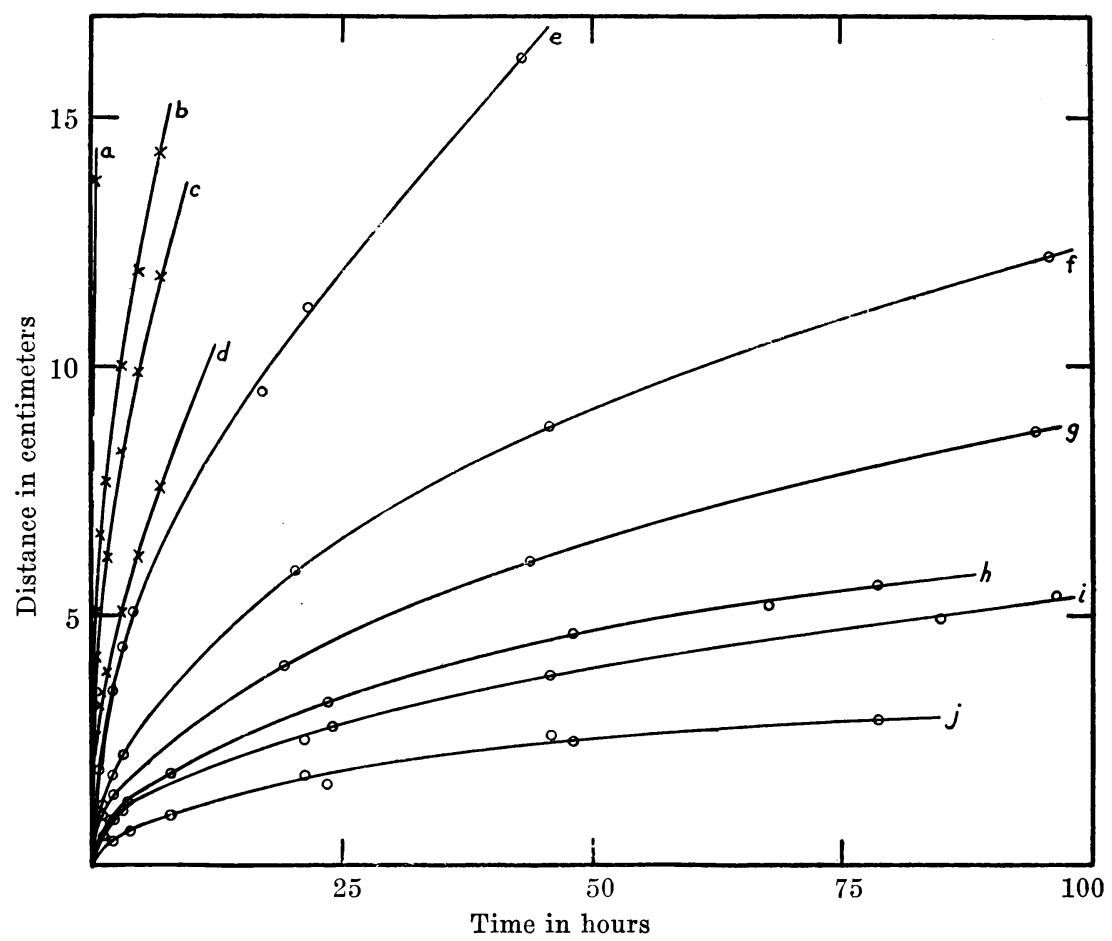

Fig. 3. Curves of distance penetrated versus time for a number of liquids in paper and in deadening felt. $a$, Kerosene in deadening felt; $b$, oil 15 in deadening felt ; $c$, oil 17 in deadening felt; $d$, oil 21 in deadening felt; $e$, kerosene in paper; $f$, oil $15+30$ per cent kerosene in paper; $g$, oil $21+30$ per cent kerosene in paper; $h$, oil 15 in paper; $i$, oil 17 in paper; $j$, oil 21 in paper.

time, $t$, a single straight line should result for all liquids in a particular porous solid. Figure 4 shows the data obtained with the typewriter paper. On account of the piling up of points only a few can be shown on the plot, but out of 38 liquids studied 21 mineral oils (including kerosene and one fly spray), pine oil, cottonseed oil, miscible oil 2, and sulfonated petroleum soap followed the equation within the limit of experimental error up to about 25 hours, and all but the most volatile of these, e.g., the fly sprays, kerosene, and pine oil 1 , followed it for about 
50 hours, after which the value of the function $\frac{2 l^{2} \eta}{\gamma_{1}}$ was increasingly less than the theoretical and the results were somewhat more scattering. Experiments in which the liquid was applied at the top of the strips showed that gravity was without effect and confirmed the previous assumption that the only appreciable force acting was the capillary force. Since this method of plotting rectifies the curves of figure 3 , it is possible from a knowledge of the spread after one time interval to calculate it

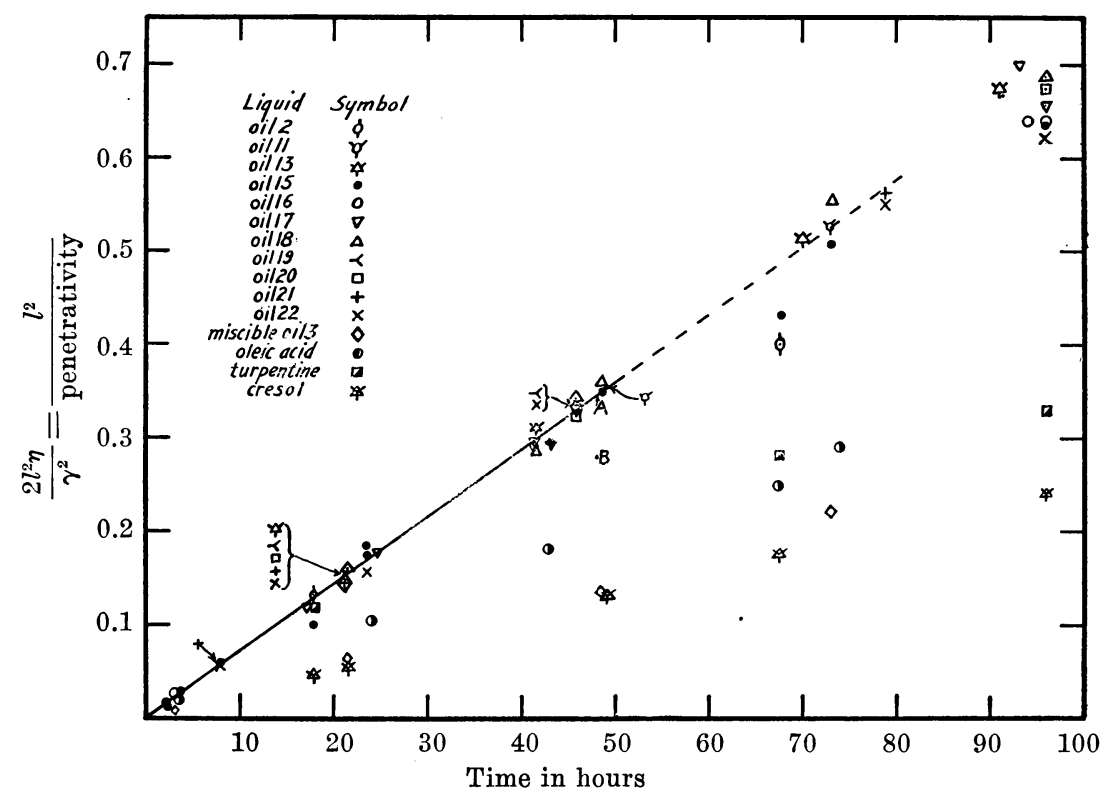

Fig. 4. Plot according to equation XII for the penetration of oils into typewriter paper.

after any other interval up to the limit at which the equation fails. By using the equation for times $t_{1}$ and $t_{2}$ it will be seen that the relation $\frac{l_{1}^{2}}{t_{1}}=\frac{l_{2}^{2}}{t_{2}}$ holds, from which the calculation follows readily. The other liquids listed in table 2 all fell below the best line drawn through the concordant results just mentioned. A few points are shown for oleic acid, turpentine, miscible oil 3, and cresol.

The fact that the majority of liquids studied obeyed the equation $\frac{2 l^{2} \eta}{\gamma_{1}}$ $=r t$ enables a quantitative rating to be established for the spread of any desired liquid. This equation may be written $\frac{l^{2}}{\frac{\gamma_{1}}{2 \eta}}=r t$, and if $r$ 
and $t$ each be taken as unity, then $\frac{\gamma_{1}}{2 \eta}=l^{2}$, or $\frac{\gamma_{1}}{2 \eta}$ is numerically equal to the square of the distance to which a liquid will penetrate a tube of unit radius in unit time when the only force acting is the capillary pressure. This quantity, $\frac{\gamma_{1}}{2 \eta}$, has been called the penetrativity (Washburn, 1921). In case the angle of contact is not zero the function $\frac{\gamma_{1} \cos \theta}{2 \eta}$ expresses the penetrativity. For the simple case the equation may be written:

$$
\frac{l^{2}}{\text { penetrativity }}=r t
$$

XII

The penetrativity provides a very convenient rating of the relative rates at which liquids will enter a porous solid, and in table 2 it is given for a number of insecticidal oils and other liquids. Not only does this function give the relative rates of entry of liquids into a porous solid

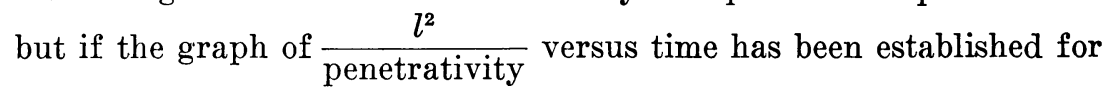
any given solid, as illustrated by figure 4 for typewriter paper, then a knowledge of the surface tension and absolute viscosity of a liquid permit its penetration to be calculated quantitatively for any desired time. For example, the penetration of kerosene at 21.4 hours can be calculated as follows: From table 2 the value of the penetrativity is $760 \mathrm{~cm}$ per sec., and from figure 4 the value of $\frac{2 l^{2} \eta}{\gamma_{1}}$ at 21.4 hours for typewriter paper is $0.162 \mathrm{~cm}$ per sec. Accordingly $l^{2}=123.1$ and $l=11.1 \mathrm{~cm}$. The experimentally determined distance is $11.2 \mathrm{~cm}$.

However, this use of the penetrativity is valid only for such liquids as show normal behavior. Referring to figure 4, consider a liquid which at any designated time, e.g., 48 hours, gave a point below the normal line as at $B$. If the penetration had been normal point $A$ on the line would have expressed the result. From equation XII it follows that $\frac{l^{2}{ }_{\mathrm{B}}}{\text { penetrativity }_{\mathrm{B}}}=\frac{l^{2}{ }_{\mathrm{A}}}{\text { penetrativity }}$ or penetrativity $_{\mathrm{B}}=\frac{l^{2}{ }_{\mathrm{B}}}{l^{2}{ }_{\mathrm{A}}}$ penetrativity $_{\mathrm{A}}$. Since point $A$ corresponds to theoretical behavior and point $B$ to actual behavior this may be written:

$$
\text { penetrativity }(\text { actual })=\frac{l^{2} \text { (actual) }}{l^{2} \text { (theoretical) }} \text { penetrativity (theoretical) }
$$

XIII

The calculation is simplified, however, by noting that this equation may be written :

$$
\text { penetrativity (actual) }=\frac{l^{2}(\text { actual })}{l_{\text {penetrativity (theoretical })}^{2}}=\frac{l^{2}(\text { actual })}{\frac{2 l^{2}(\text { theoretical })}{\gamma_{1}} \eta}
$$


or the actual penetrativity is obtained by dividing the square of the distance actually penetrated at any time by the ordinate of the line in figure 4 which corresponds to that time. For example, consider turpentine, which departs rather widely from normal behavior after 20 hours. At 24 hours the experimentally determined value of $l^{2}$ (taken from a graph of $l$ versus $t$, similar to figure 3 ) is 114.8. The corresponding value of $\frac{2 l^{2} \eta}{\gamma_{1}}$ (fig. 4) is 0.173 . Hence the penetrativity (actual) is $664 \mathrm{~cm}$ per sec. instead of the value $775 \mathrm{~cm}$ per sec. as shown in column 7 of table 2 . At 48 hours a similar calculation gives an actual penetrativity of 524 cm per sec. In column 8 of table 2 the actual penetrativities of those liquids which depart from normal in penetrating typewriter paper are given for 24 hours. This is, unfortunately, not a constant for any given abnormal liquid but varies somewhat as different solids are used. A further discussion of these "abnormal" liquids will be given under the heading "Total Spread of Solutions," page 76. Among liquids so far studied all mineral oils acted normally and only exceptionally volatile or reactive materials were found to be abnormal, so that it is usually possible to predict the occurrence of abnormal rate of spreading from a knowledge of the chemical properties of the substance in question. Furthermore, abnormal behavior of materials that are not mixtures was always in the direction of less-than-the-expected rates of spread.

Just as the penetrativity gives a rating of the relative rates of penetration of various liquids into a given porous solid, so does the slope of the straight line in graphs such as figure 4 give a rating of the relative rates of penetration of a given liquid into various solids. In the case of typewriter paper the slope is constant up to about 50 hours (except for the most volatile liquids). The numerical value of this slope is obtained by dividing the ordinate $\frac{2 l^{2} \eta}{\gamma_{1}}$ by the abscissa $(t)$. In figure 4 the viscosity, $\eta$, has been expressed in poises and $t$ in hours. But to obtain $r$ in centimeters it is necessary for $t$ to be in seconds. Allowing for these conditions and using the data at 48 hours, $r=\frac{34.6}{100 \times 48 \times 3,600}=2 \times$ $10^{-8} \mathrm{~cm}$. While the term $r$ has been regarded as the radius of a capillary tube or the fourth root of the average fourth power of the radii of the capillaries in a porous solid, it should not be regarded as expressing a numerical measure of the capillary size in such a material as paper, in which the capillary spaces are not all parallel but are arranged haphazard and furthermore vary through a wide range of length with spaces of unknown size and shape connecting the true capillaries. For these reasons the above value of $r$ is regarded not as a radius of capil- 
laries but rather as a measure of the relative ease with which liquids can enter such a solid.

Figure 3 also shows the $l$ versus $t$ curves for a few oils penetrating deadening felt, and in figure 5 the $\frac{2 l^{2} \eta}{\gamma_{1}}$ versus $t$ data are represented. Excellent agreement among a considerable number of oils is again shown, but the line begins to curve when the time reaches about 1 hour. Since penetration is very rapid into this material and a height of several centimeters was reached by the end of an hour, this departure from

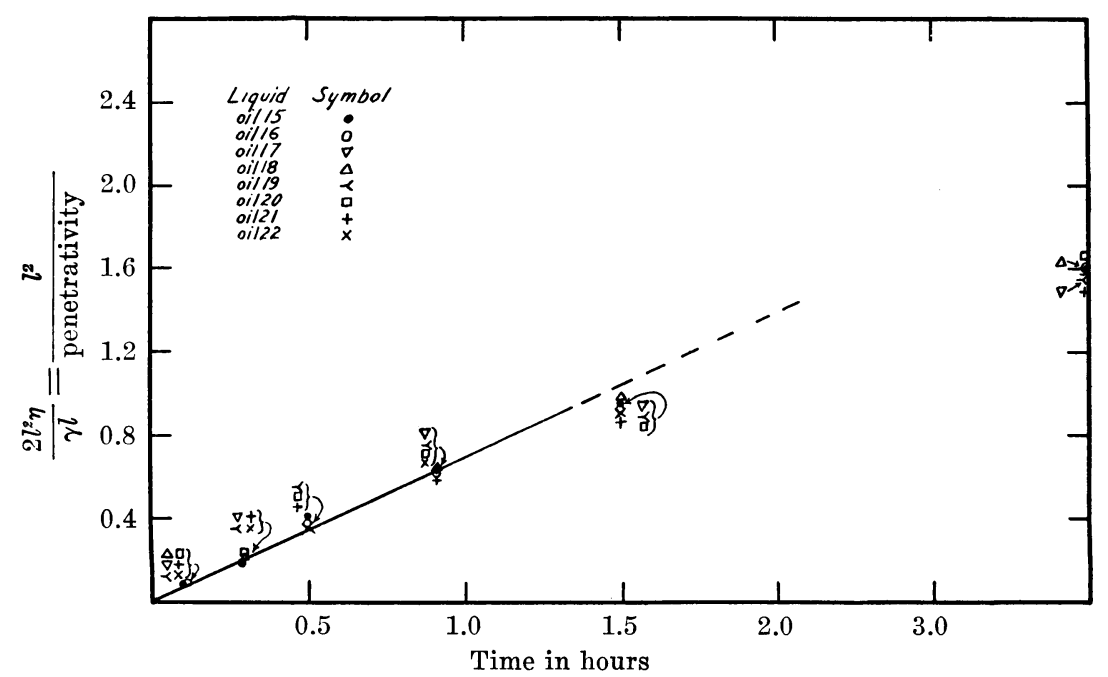

Fig. 5. Plot according to equation XII for the penetration of oils into deadening felt.

ideal conditions is to be expected and corresponds to the similar behavior shown in the case of typewriter paper after about 50 hours had elapsed. Calculating the value of $r$ for this material in the same way as was done for the typewriter paper, the data for one hour's spread give $r=$ $\frac{69}{100 \times 3,600}=192 \times 10^{-6} \mathrm{~cm}$. Since the corresponding term for the typewriter paper is $2 \times 10^{-6} \mathrm{~cm}$ it may be seen that the deadening felt is much more readily permeable. It will be noted that since $l^{2}$ is proportional to $r$ the following relation holds (for equal times of spread) $\frac{l^{2} \text { (paper) }}{r \text { (paper) }}=\frac{l^{2} \text { (felt) }}{r \text { (felt) }}$. The accuracy of this equation may be tested by the data for oil 17. For one hour's penetration into felt the value of $l^{2}$ for oil 17 is 24.8 . Hence for the same interval into paper $l^{2}=\frac{2}{192} \times$ 
$24.8=0.258$ or $l=0.5 \mathrm{~cm}$, which agrees exactly with the experimentally determined value. By using the relation between penetration and time previously cited, namely $\frac{l_{1}^{2}}{t_{1}}=\frac{l_{2}^{2}}{t_{2}}$, the spread in paper may be calculated for any time up to about 50 hours, e.g., for 48 hours $l$ is calculated to be $3.52 \mathrm{~cm}$. Experimentally it was found to be $3.5 \mathrm{~cm}$. These examples are given to show how from comparatively few data a fairly complete knowledge of the penetration of insecticidal oils into porous materials may be obtained.

Straight Oils in Bark.-Dince one objective of this study on the penetration of oils was to aid in understanding what occurs when oils are applied to bark, work was undertaken on this problem. Sections of bark were removed from the trunks of various trees and grapevines. If the bark was composed of layers, as in the case of grapes, pieces of each layer were cut into strips about $5 / 8$ inch in width and long enough to fill the test tubes. If the bark was not in layers, as in the case of oak, it was cut or sawn into sheets at various depths from the outside and strips cut as before. The rate of penetration of oils was measured exactly as for the paper and felt strips. It became apparent at once that lack of uniformity of structure in the bark leads to great variations in the rate of flow, and many strips were necessary in order to obtain an average behavior of reasonable accuracy. Also each layer of a particular bark has a different rate of penetration. Upon plotting the $\frac{2 l^{2} \eta}{\gamma_{1}}$ versus $t$ values for various oils penetrating each layer of a particular bark, it was shown that the heavier oils ( $\eta \overline{\overline{ }} 0.25$ poises) gave a fairly definite straight line for several hours' penetration, but lighter oils and particularly kerosene fell far below these lines in each case. In searching for an explanation of this behavior, microscopic observation of the surface of strips of bark as oils advanced through them showed that the tiny pieces of resin dissolved readily in kerosene but increasingly slower in heavier oils. Since solution of this material would greatly increase the viscosity, especially of very fluid liquids, it seems likely that variations from normal behavior are largely due to this cause. Using the straight lines defined by the penetration of heavier oils, tentative values of $r$ were calculated to be :

\begin{tabular}{|c|c|}
\hline 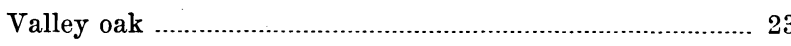 & $23 \times 10^{-6} \mathrm{~cm}$ \\
\hline Eucalyptus. & $34 \quad 6$ \\
\hline Black walnut & “ \\
\hline 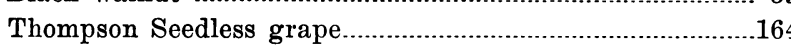 & “ \\
\hline
\end{tabular}

These are all for intermediate layers or sections of bark. Without citing data it may be qualitatively stated that outer layers are more readily 


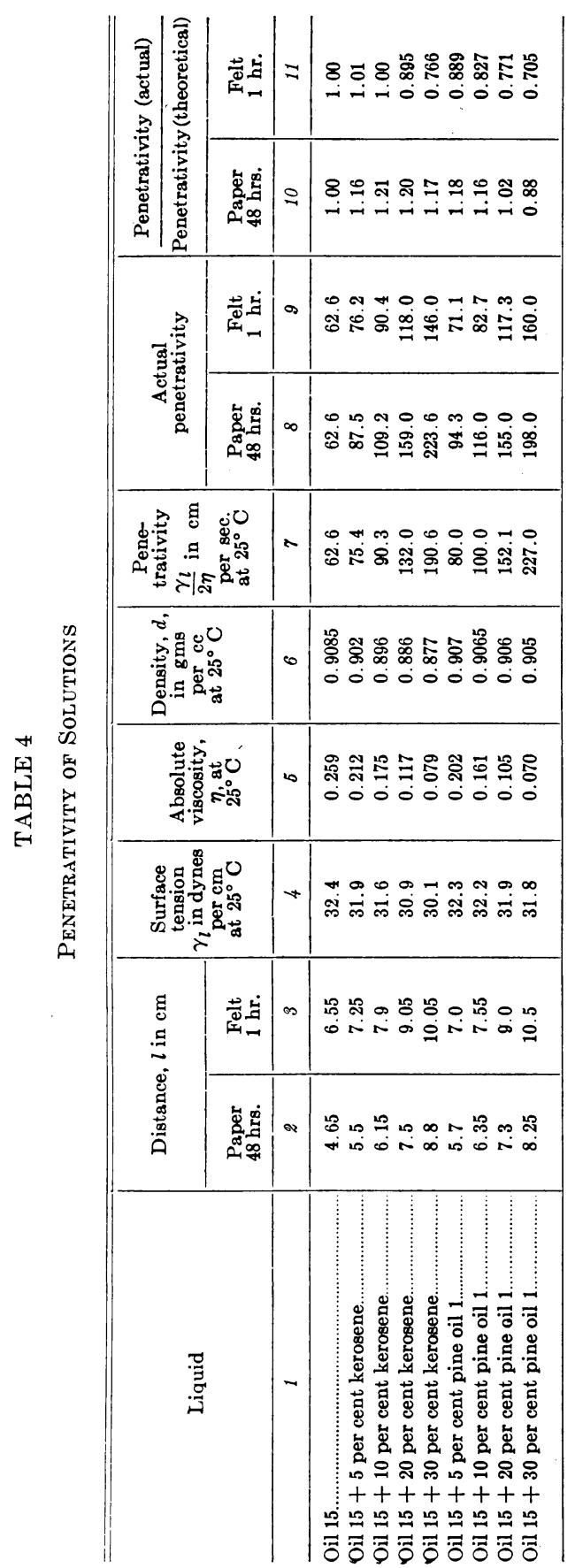


penetrated and inner layers less readily than the intermediate. The barks studied appear to lie between typewriter paper and deadening felt as regards ease of penetration. A systematic study of penetration of insecticidal oils into various kinds of bark is in progress and will be reported upon at a later time.

Solutions in Paper and Felt.-The oils previously considered have all been "straight cuts," and comprised the compounds coming over during distillation within a comparatively narrow temperature range. One way to decrease the viscosity of an oil greatly is to add a small percentage of a very fluid material such as kerosene. At the same time the surface tension is but slightly affected. Accordingly, such solutions should penetrate porous materials much more readily than the original oils. To test this hypothesis, $5,10,20$, and 30 per cent solutions by volume of kerosene and of pine oil 1 (hereafter called the solutes) were prepared in oils 15, $17,20,21$, and 22 , and their rates of entry into the two solids, typewriter paper and deadening felt, were studied. Figure 3 gives the data for some of the solutions. The surface tensions, viscosities, and densities were determined as for the straight oils and the data for the solutions in oil 1.5 are included in table 4, which also gives the distances penetrated into the paper after 48 hours and the felt after 1 hour. The considerable increase in the distances penetrated runs parallel with the increases in percentage of solute and shows that small additions of such materials have very decided effects. The actual penetrativities, calculated as explained previously, are given in columns 8 and 9 . When the ratio of actual to theoretical penetrativity is calculated (cols. 10 and 11) it will be noted that in the case of penetration into paper this ratio goes through a maximum at 5 to 10 per cent of solute, whereas in felt the ratio decreases with both solutes, though more rapidly with the pine-oil solutions. The circumstances that the actual penetrativity exceeds the theoretical is opposite to the case with the reactive or volatile compounds previously noted. An additional factor enters into the behavior of solutions, i.e., separation of components. This phenomenon has been studied, particularly for the case of aqueous solutions, and has usually been attributed to preferential adsorption of one component on the porous solid (Freundlich, 1930). As a result of this both the surface tension and the viscosity within the rising column are changed. To calculate the $\frac{2 l^{2} \eta}{\gamma_{1}}$ versus $t$ relation for solutions it is necessary to know (1) $\eta$ versus concentration of solute for the whole range of concentration (because at the top of the ascending column the component of lower surface tension may be practically pure) and (2) concentration of the solute at each point in the ascending column. From these data the relation of $\eta$ 
to $l$ could be found and the theoretical penetrativity corrected accordingly. In any particular case the same information ( $\eta$ to $l$ relation) could be found experimentally by allowing the solution to rise in a roll of porous medium as was done by Fischer and Schmidmer (1893) in their study of the separation of various salts as aqueous solutions rose in filter paper. By determining the viscosity of the contents of segments of the roll at various heights above the liquid this relation of viscosity to distance risen could be found. That different solids cause separation of components to varying extents is indicated by the difference in the ratio of actual to theoretical penetrativity for paper and felt. The similar solutions of kerosene and pine oil in the other oils acted likewise.

That separation of components occurred in the present instance was proved by allowing one end of the paper strip to extend beyond the cork at the top of the test tube. The rising column of liquid extended in the course of time beyond the cork to the distance of a centimeter or so but then practically ceased to rise during a period of a few hours to a couple of days, according to the amount of solute in the solution. After this delay spreading was resumed. Obviously, the more volatile component had become concentrated at the top of the column and evaporation from the exposed strip had equaled the entry of fresh liquid until appreciable amounts of the heavier component had arrived. It is plain from the foregoing discussion that the rate of penetration into porous solids of mixtures containing components of very different characteristies does not obey the relatively simple laws that hold for straight-cut oils.

\section{MEASUREMENT OF TOTAL SPREAD}

These experiments were carried out in two ways. In the first method, called for convenience the "closed" type, a few cubic centimeters of the liquid were placed in the bottom of a test tube and a $5 / 8$-inch strip of the solid approximately 6 inches long was fastened to a cork so that its lower end would be about a centimeter above the liquid when the cork was put into place firmly. Two pins at right angles through its lower end prevented the strip from touching the tube. A measured quantity of liquid was then allowed to run onto the lower end of the strip from a capillary pipette and the strip and cork were put into place in the test tube. The liquid at the bottom of the test tube was for the purpose of keeping the space saturated with vapor so that evaporation from the strip would be reduced to a minimum. Observations were made of the extent of spread without disturbing the arrangement. For typewriter-paper strips 0.035 cc of liquid was used and for felt strips $0.10 \mathrm{cc}$, since these volumes gave 
total spreads as great as possible without exceeding the length of strip in any case.

Before discussing the results of experiments on total spread it is worth noting that so long as any portion of the liquid on the strip remained unabsorbed the rate of spread was identical with that found when the strip dipped into the liquid at the bottom of the tube, as in the arrangement for measuring rates of spread. Thus after 21.5 hours oil 15 had penetrated for a distance of $3.05 \mathrm{~cm}$ as compared with $3.1 \mathrm{~cm}$ in the other set-up. The time during which behavior thus conformed to the relation $\frac{l^{2}}{\text { penetrativity }}=r t$ (equation XII), was only a few hours in the case of liquids of high penetrativity and persisted for nearly two days for those of very low penetrativity. This indicates that so long as any unabsorbed oil was present the theoretical law for rate of penetration was obeyed. As before, the mineral oils comprised most of the substances obeying this law. The time at which all unabsorbed oil vanished could be determined visually with fair certainty.

The second type of experiments on total spread (called the "open" type) consisted in applying the same volume of the liquid to the lower end of strips identical with those previously described and hanging by the upper end from a horizontal bar. The strips were placed far enough apart so that slight breezes, such as occasionally swept through the laboratory, did not cause them to touch one another. This method was designed to allow full opportunity for evaporation, such as occurs whenever liquids are used as sprays in the open.

It has not been found possible to deduce a theoretical expression, in terms of experimentally determinable properties, for the total spread of a given quantity of a liquid through a solid. Accordingly, attention has been directed to determining the effect upon total spread of variations in each of several properties of the liquids used. These will be discussed as far as is practical for both "closed" and "open" conditions of spreading. The fact that several properties of spray oils vary together makes it difficult to study the effect of variation in only one at a time.

Viscosity.-It doe not seem probable thas viscosity, per se, would have an appreciable effect upon total spread either "closed" or "open." As discussed previously, the rates of penetration of liquids into porous solids are inversely proportional to the viscosities of the liquids, but total spread is the distance ultimately penetrated regardless of whether reached within a few hours or after several months as actually occurred in several cases. Columns 4 and 5 of table 5 show that the time required to reach equilibrium in either "closed" or "open" penetration is dependent upon the viscosity. By thus prolonging the time required to 


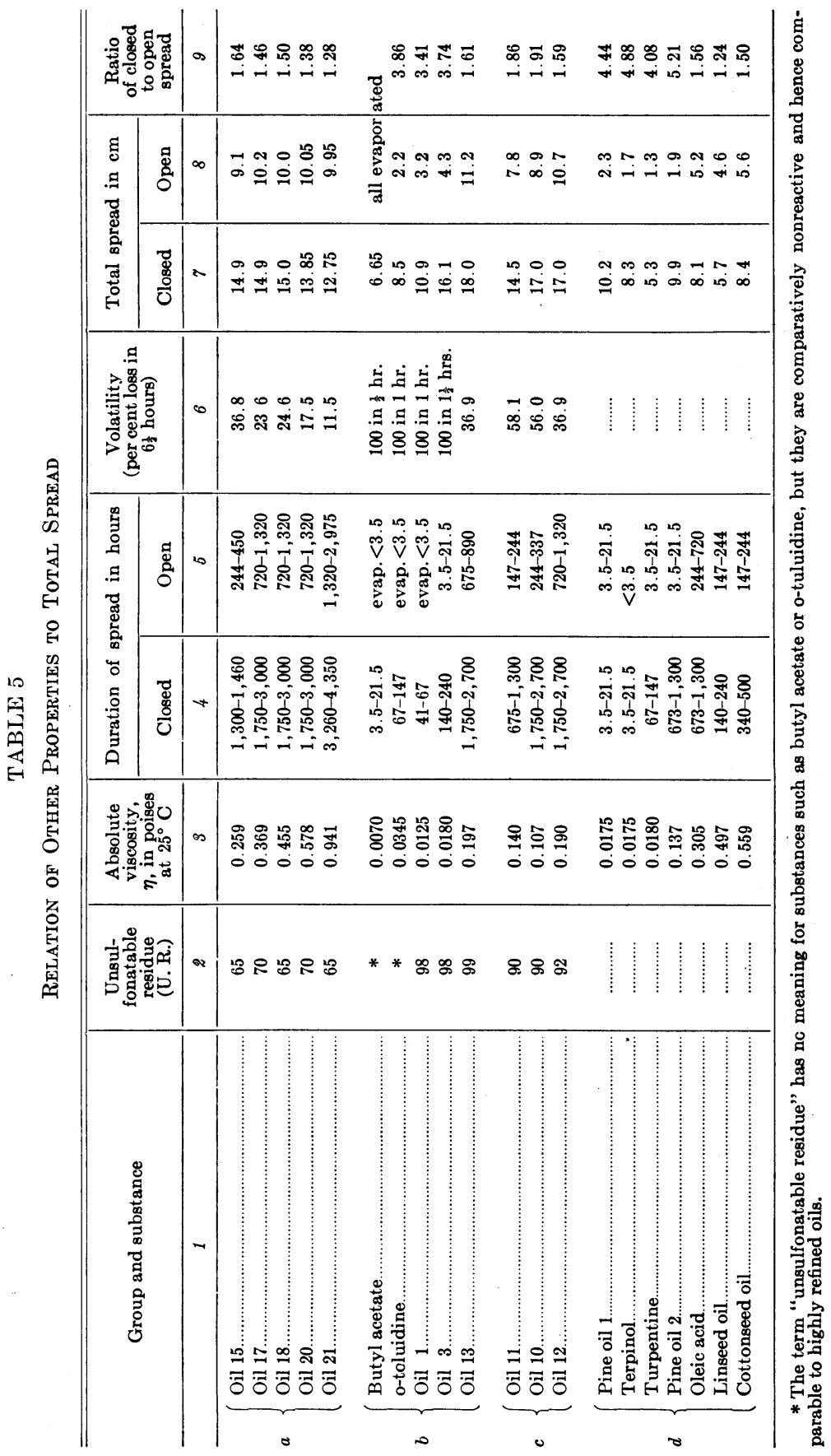


reach the full extent of spreading, a high viscosity increases the loss by evaporation and the extent of reaction with the air, which results in gummy substances that spread but little. This latter circumstance particularly concerns oils of low refinement. In column 7 of table 5 it will be noted that the oils of group $a$ in the "closed" tests spread to the same extent within the limit of experimental error until the absolute viscosity exceeded 0.455 poises (Saybolt viscosity was 105 seconds at $100^{\circ}$ $F$ for that particular oil). The two oils of higher viscosity showed a marked falling-off in total spread. In the case of the highly refined substances of group $b$ the most viscous one spread the farthest and the variations in spread can be explained in terms of volatility.

Volatility.-The great effect of this property upon total spread is well illustrated in table 5. Among the compounds of group $a$, all of which are but slightly volatile, the only effect was that the "open" spread of the most volatile material, oil 15, was diminished. Among the substances of group $b$ this effect was very marked for both types of spread. This may seem peculiar in the case of "closed" spread in which an attempt was made to keep the space within the test tube saturated with the vapor of the liquid concerned. However, some of this vapor was adsorbed in the solid shortly after its introduction and the small surface of the liquid in the bottom of the tube prevented the maintenance of saturation thereafter. Consequently, material of high volatility evaporated from the rising column and was adsorbed above with the result that the total "closed" spread was shortened. This state of affairs was very clearly manifested with o-toluidine, which spread only $8.5 \mathrm{~cm}$, although the entire portion of the strip above was colored a distinct brown. Other volatile substances did not impart a color to the upper part of the strips but a change in reflecting power was easily noted, e.g., with pine oil 1. The materials of group $c$, which are of intermediate volatility, showed the same effect of volatility upon the total spread. This effect of volatility doubtless was present in the determinations of rate of spread, but since the time was very short the error involved was entirely negligible.

If the ratio of total spread "closed" to total spread "open" is calculated for the spray oils of table 5 and plotted against the volatility, a straight line results, as may be seen by plotting column 6 versus column 9. If the volatility were expressed by the percentage evaporated after some other time than $61 / 2$ hours on the steam bath, such close agreement might not be found, but the general truth of the relation is evident.

Surface Tension and Penetrativity.-Neither surface tension nor penetrativity has a direct relation to total spread of either type. However, in a graph of total spread "closed" versus penetrativity (fig. 6) 
for all materials listed in table 2, the spray oils of penetrativity between 17 and $140 \mathrm{~cm}$ per sec. all lie in a group having total spread between 12.2 and $18.0 \mathrm{~cm}$ and fairly definitely determine a line in the upper lefthand corner of the graph. All other materials of the table lie far below or to the right of this line. All substances of high volatility or reactivity gave much less total spread than their penetrativities would indicate. Since the penetrativity involves the viscosity this graph illustrates very forcibly the result of loss in spreading power due to evaporation or reaction with the air, as discussed before. Total spread "open" showed the same effect to an even more marked extent.

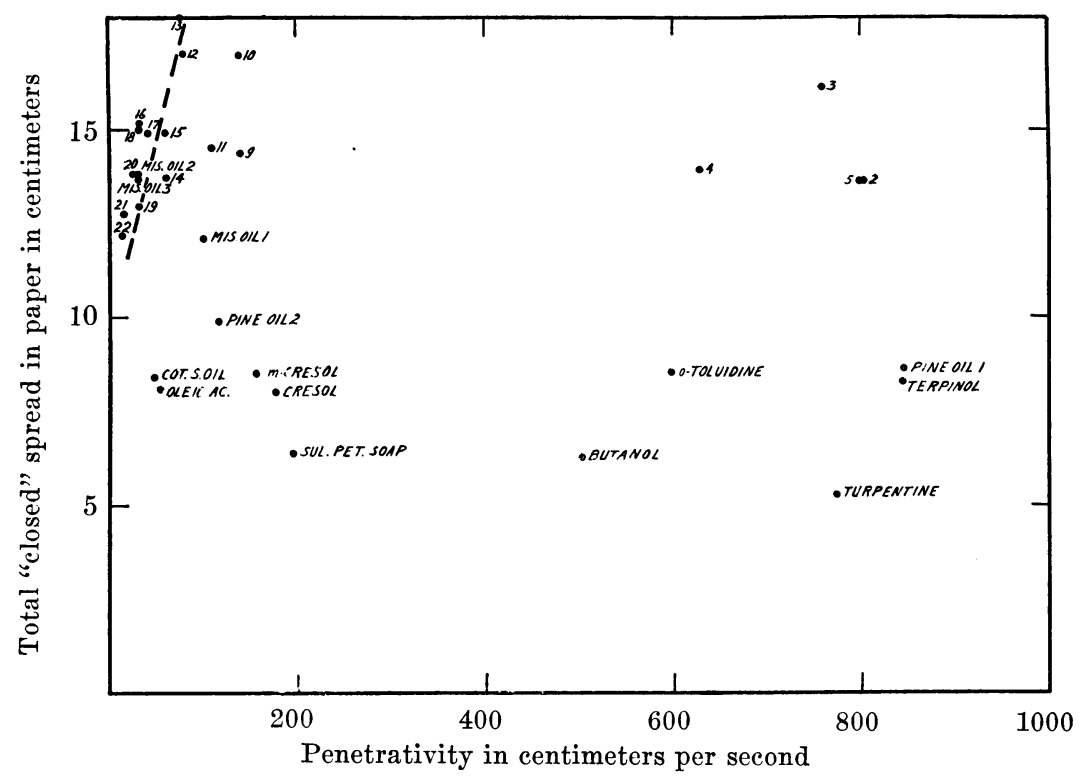

Fig. 6. Relation of penetrativity to total "closed spread" in paper. Numbers correspond with numbers of oils in table 2.

Refinement.-In the case of spray oils the degree of refinement is measured by the change in volume when an oil is treated with concentrated sulfuric acid under standard conditions (Elmore, 1931), and the results are expressed in terms of unsulfonatable residue. The unsulfonatable residue (U.R.) is thus a measure of the compounds which are too inactive chemically to be affected by hot, concentrated sulfuric acid. From the standpoint of oils as spray material the U.R. is of importance both as regards ease of oxidation by the air and effect upon plants and insects (Gray and deOng, 1926; deOng, 1931). In spread through an inert porous solid, oxidation by the air is the principal factor concerned. Table 5 shows that the total spread either "closed" or "open" is influ- 
enced by the degree of refinement, e.g., oils 15,12 , and 13 are closely alike in all properties except unsulfonatable residue (which was 65, 92, and 99 respectively) and their total spreads are 14.9, 17.0, and 18.0 cm "closed" and 9.1, 10.7, and $11.2 \mathrm{~cm}$ "open," respectively.

Another illustration of the same behavior is afforded by the total spread "closed" in felt strips of a number of oils in atmospheres of air and nitrogen. Typical of many results are those in table 6 . In an inert atmosphere no difference in total spread was found, but in air the most reactive oil spread the least.

TABLE 6

EFFeCt of Atmosphere Upon Total Spread

\begin{tabular}{c|c|c|c|c|c}
\hline Oil & $\begin{array}{c}\text { Unsol- } \\
\text { fonatable } \\
\text { residue }\end{array}$ & $\begin{array}{c}\text { Viscosity, } \\
\text { in } \\
\text { poises }\end{array}$ & $\begin{array}{c}\text { In air, } \\
\text { in cm }\end{array}$ & $\begin{array}{c}\text { In nitrogen, } \\
\text { in cm }\end{array}$ & Spread in nitrogen \\
\hline 1 & 2 & 3 & 4 & 5 & Spread in air \\
\hline 8 & 70 & 0.064 & 9.6 & 10.0 & 6 \\
\hline 7 & 89 & 0.062 & 9.8 & 10.0 & 1.04 \\
& 99 & 0.057 & 10.0 & 10.0 & 1.02 \\
\hline
\end{tabular}

Effect of Amount of Liquid on Total Spread.-It might be expected that the total spread of a highly refined oil under conditions minimizing evaporation would be closely proportional to the volume used, but that with volatile or reactive materials larger volumes would not spread as far as would be indicated by the spread of small volumes because of the longer time of spreading. To test this point various volumes of several substances were used with paper strips under "closed" conditions with the results shown in table 7 . These results show clearly that total spread

TABLE 7

EFfect of Volume Upon Total Spread

\begin{tabular}{|c|c|c|c|}
\hline \multirow{3}{*}{ Material } & \multicolumn{2}{|c|}{ Actual total spread "closed", in cm } & \multirow{3}{*}{$\begin{array}{l}\text { Calculated for } 0.35 \\
\text { cc from0.020 result, } \\
\text { in } \mathrm{cm}\end{array}$} \\
\hline & \multicolumn{2}{|c|}{ Volume } & \\
\hline & $0.020 \mathrm{cc}$ & $0.035 \mathrm{cc}$ & \\
\hline 1 & 2 & 3 & 4 \\
\hline Mineral oil 13 & 10.3 & 18.0 & 18.0 \\
\hline Mineral oil 3 & 9.3 & 16.1 & 16.3 \\
\hline 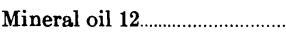 & 11.0 & 17.0 & 19.2 \\
\hline 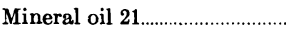 & 10.4 & 13.1 & 18.2 \\
\hline 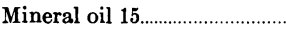 & 11.4 & 14.2 & 19.6 \\
\hline Linseed oil ..................... & 5.1 & 5.7 & 8.9 \\
\hline Cottonseed oil ........................... & 5.2 & 8.4 & 9.1 \\
\hline Pine oil 2 & 8.1 & 9.9 & 14.2 \\
\hline 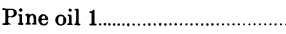 & 8.6 & 11.6 & 15.0 \\
\hline
\end{tabular}


is less and less proportional to volume used as the liquid is more volatile or reactive.

Another question of considerable importance concerns the effect of adding another portion of oil to a strip in which spreading has reached equilibrium. To strips in which oils 15, 18, and 17 had completed their spread under "closed" conditions an additional 0.035 ec of each was added. The fresh oil could be seen ascending the strips and within 16 to 24 days, the time depending upon the viscosities of the oils, the limit of original spread was reached. Without pausing at this point each oil continued to spread until, after periods of about 40 to 60 days more, equilibrium was again reached. The extent of additional spread was very little, however, being $2.0,2.2$, and $1.9 \mathrm{~cm}$ for oils 15,18 , and 17 respectively. Experiments with other oils and with solutions containing kerosene, sulfonated petroleum soap, etc., corroborated this finding that the addition of more liquid results in but little more spread, probably because of evaporation during the long time of spreading.

Total Spread of Solutions.-The same solutions of the five oils with kerosene and with pine oil 1 , that were mentioned under rates of spreading, were used to determine their total spread through paper strips. Under conditions of "closed" spreading an increase resulted, roughly proportional to the percentage of solute added. On the other hand the total "open" spread was decreased proportionally. The results may be summarized briefly by stating that the solutions containing 30 per cent kerosene gave an average increase in "closed" spread of $3.5 \mathrm{~cm}$ as compared with the five straight oils, whereas in "open" spread the average decrease was $1.1 \mathrm{~cm}$. These are 25 per cent and 11 per cent, respectively, of the total average spreads of the straight oils under the same two conditions. With the corresponding pine-oil solutions the increase averaged $2.7 \mathrm{~cm}$ (20 per cent) and the decrease averaged $0.6 \mathrm{~cm}$ ( 6 per cent). Solutions of the same oils containing 30 per cent of a sulfonated petroleum soap spread less than the straight oils under both conditions, the decreases being $1.2 \mathrm{~cm}$ (9 per cent) "closed" and $2.1 \mathrm{~cm}$ (22 per cent) "open." The addition of kerosene or pine oil or sulfonated petroleum soap to the highly refined oil 13 led to a decrease with both "open" and "closed" spreads.

Similar experiments with deadening felt gave no results because the total spreads could not be determined accurately. Preliminary work with bark showed that the solvent effect of very light oils upon the bark resins therein decreased the total spreads just as it decreased the rate of spread. 


\section{DISCUSSION}

The foregoing account of the entrance of a liquid into a porous solid has shown the physical necessity for the filling of pores and cavities of all sizes near the point of entry when there is an abundance of liquid. After all the liquid has entered such cavities a redistribution occurs during which all the liquid except a thin coating leaves the larger openings and enters smaller ones at the limit of spread. The whole process can be observed readily by placing a drop of oil on a piece of filter paper and viewing it through a low-power microscope. An instrument equipped with a vertical illuminator is particularly useful in watching the sequence of events.

From the data obtained on rate of spreading and total spread certain conclusions can be drawn concerning the type of oil capable of giving the greatest spread in such porous materials as bark. In the first place it should be noted that there is considerable difficulty in applying suffcient oil to completely fill the bark of such a trunk as that of a grapevine or of a tree with thick bark, and if enough oil is used to accomplish this the cost becomes excessive. Hence a material which spreads far is necessary. The characteristics which contribute to this property have been shown to be : high refinement, low viscosity, and low volatility. Increase in cost mounts rapidly with the degree of refinement, but oils of refinement intermediate between typical winter and summer grades spread well and are not very much more expensive than those of low refinement. Since the viscosities of oils having the same volatility are lower the greater the ratio of hydrogen to carbon, i.e., the more completely saturated the molecules are (Dunstan and Thole, 1918), it would be very interesting to study the relative penetration of paraffin-base and asphaltic-base oils, which differ decidedly in this ratio.

Unfortunately, petroleum oils of any origin, which have really low viscosities, e.g., kerosene, are all rather volatile and their total spreads, particularly in the open, are accordingly lessened. A compromise is necessary between the two properties, the choice in any particular case depending upon the distance through which oil must penetrate to get to the insect concerned. Another reason why oils of very low viscosity are not satisfactory for use in bark is their solvent effect on resins, which results in greatly reduced penetration unless very large amounts of oil are used.

It has been noted that if an oil spreads rapidly enough the losses by evaporation and reaction with the air are lessened. This rate of spread- 
ing depends upon the penetrativity, which varies directly as the surface tension and inversely as the viscosity. Since the surface tensions of oils fall within rather narrow limits and since components of low surface tension always gather at an interface (Rideal, 1930, p. 48-58), it does not seem possible to profit by increasing this property. On the other hand, the viscosity is readily and decisively lowered by the addition of a small percentage of very fluid solutes. Since the actual penetrativity of such solutions is greater than the calculated value when the solid is difficult to enter, such solutions offer promise of being very useful. Search should be made for substances of low volatility and low viscosity which are freely soluble in oils. Cresol or cresylic soaps do not satisfy the need, for in table 2, it will be noted that the actual penetrativities of the miscible oils were considerably less than the calculated values, and data not shown in the tables indicated that both types of total spread were considerably less than were obtained with straight oils of similar properties. Vegetable oils also failed to give promise, as indicated in table 5, group $d$. It is not impossible, however, that vegetable oils with the unsaturated compounds removed might be of value in conjunction with mineral oils, especially since some have been found to be decidedly toxic (Siegler and Popenoe, 1925; Tattersfield and Gimingham, 1927).

Preliminary field trials have borne out the conclusions discussed above. Thompson Seedless (Sultanina) and Alicante grapevines were sprayed with a number of oils and mixtures during the dormant season and account was taken of the penetration through the bark and the percentage of hibernating red spiders that were killed. Very briefly summarizing this work, it may be said that very volatile materials such as oil 1 (a fly spray), kerosene, and pine oil 1 penetrated very rapidly but were apparently all evaporated within a few hours and very little kill was obtained; complete penetrations and fairly high kills were obtained with such materials as oils 12 and 15; and unsatisfactory penetrations and kills were obtained with oils of high viscosity.

The important topic of using oils as carriers for such toxic substances as naphthalene and paradichlorobenzene has not yet been studied in the present work. It is usually held that such carrying action occurs, but the separation of components noted with solutions of two liquids gives rise to doubt as to what happens when one component is a dissolved solid.

No mention has been made so far of the effect of moisture in the solid. That is not usually concerned when oils are applied straight unless a rain has come just before spraying must be done. But the penetration of oils from water emulsions is directly connected with the effect of water 
upon the penetration of oil through solids. Felt strips were suspended in test tubes above a layer of water and left for one week by which time saturation with water vapor may be assumed to have been reached. A volume of oil $(0.10 \mathrm{cc})$ was then placed at the bottom of the strip and the spread observed. With all six of the oils so studied the rate of penetration was less than with dry strips, and the final spread attained was also decreased. To test the ease of replacement of water by oil, or vice versa, opposite ends of strips of filter paper and of deadening felt were dipped into oil and into water contained in two beakers standing side by side and both being within a covered battery jar. The air within the jar was thus saturated with both water and oil vapor. Under such conditions the line of contact between the water and oil was very sharp and no movement in either direction could be detected in several weeks. However, if the cover was removed from the battery jar so that the water could evaporate from the strip the oil advanced steadily until it nearly reached to the water level in the opposite beaker. This experiment indicates that when an oil emulsion is sprayed upon bark, the water, being present in great excess, soaks into the bark, particularly the outer layers, and the only oil deposited is a very little upon the very outer surface. As the water then evaporates the oil penetrates into the bark. This explains why it was found quite impossible to apply enough oil emulsion to grapevines to penetrate to the hibernating red spiders.

\section{SUMMARY}

The rate of penetration of liquids into a porous solid has been shown to be controlled by a property of the liquid, the penetrativity, and by a property of the solid, the average radius of its pores. The penetrativity is a function of the surface tension and the absolute viscosity of the liquid. A standard method of studying the rate of penetration has been employed in which strips of the solid (paper, deadening felt, or bark) were dipped into oils and other liquids at the bottom of test tubes. Mineral oils were found to follow the theoretical behavior, but very volatile or reactive materials spread less rapidly than predicted. The solvent action of light oils upon the resin in bark decreased the rate of penetration.

For a wide variety of spray oils the penetrativity gave a measure of the relative rates of entry, and from graphs of spread, penetrativity, and time, the relative ease of entrance into various solids could be determined. Data on surface tension, absolute and Saybolt viscosities, density, unsulfonatable residue, volatility, and penetrativity are given, 
together with details of the methods of determination. Solutions containing 5 to 10 per cent of a very fluid substance such as kerosene spread somewhat faster than was calculated from their penetrativities. This was shown to be due to separation of the components.

The total spread of known volumes of liquids through the same solids was studied by adding the liquids to strips either hung in closed test tubes or in the open air. No theoretical calculation of total spread could be made. Viscosity is important because it controls the time until maximum spreading is attained, and hence opportunity for evaporation and reaction with the air increases as the viscosity becomes greater. Volatility is of great importance especially when evaporation occurs freely. The higher the degree of refinement the greater the spread of oils, both in the open and within closed containers. Increasing the volume of oil gave spreads less than proportional to the volumes used, and the addition of more oil after spreading had ceased resulted in but little additional spread. Addition to the oils of fluid materials such as kerosene increased the total spread when evaporation was prevented but decreased it in the open.

The rate of spread and the total spread were decreased by adding moisture to the strips. The difficulty of applying enough oil in aqueous emulsions is discussed. Preliminary field experiments bore out the need for using oils of fairly high refinement, low viscosity, and low volatility in as far as these properties are mutually compatible.

\section{ACKNOWLEDGMENTS}

It is a pleasure to express gratitude to Dr. J. F. Lamiman, who conducted the field tests previously mentioned, and to Dr. R. Craig, whose helpful suggestions were of the greatest value throughout the work. 


\section{LITERATURE CITED}

BARTELL, F. E., AND H. J. OSTERHOF.

1928. The pore size of compressed carbon and silica membranes. Jour. Phys. Chem. $32: 1553-1571$.

BeLl, J. M., and F. K. Cameron. 1906. The flow of liquids through eapillary spaces. Jour. Phys. Chem. 10:658-74.

Bingham, E. C., AND R. F. JACKson.

1917. Standard substances for the calibration of viscometers. U. S. Dept. Comm. Bur. Standards Sci. Paper 298:86-95.

BoDINE, J. H.

1923. Hibernation in Orthoptera. Jour. Exp. Zool. 37:457-76.

DE ONG, E. R.

1931. Present trend of oil sprays. Jour. Econ. Ent. 24:978-85.

DU Noür, P. L.

1925. An interfacial tensiometer for universal use. Jour. Gen. Physiol. 7:625-31.

Dunstan, A. E., and F. B. Thole.

1918. Relation between viscosity and chemical constitution of lubricating oils. Petrol. Rev. 38:245-6; 267-8.

ELMORE, J. W.

1931. Economic poisons. California State Dept. Agr. Special Pub. 107:1-64.

Fischer, E., AND E. SChMidMer.

1893. Über das Aufsteigen von Salzlösungen im Filtrirpapier. Liebig's Ann. Chem. 272:156-69.

Francis, C. K., and H. T. Bennett.

1922. The surface tension of petroleum. Jour. Indus. and Engin. Chem. 14:626-8.

Freundich, H.

1930. Kapillarchemie. Band I. 566 p. (See specifically p. 309-314.) Akademische Verlagesellschaft. M. B. H., Leipzig.

GinsburG, J. M.

1931. Penetration of petroleum oils into plant tissue. Jour. Agr. Research 43: 469-74.

Gray, G., AND E. R. DE ONG.

1926. California petroleum insecticides. Jour. Indus. and Engin. Chem. 18:175-80.

HaRKINS, W. D., AND H. F. JoRdan,

1930. A method for the determination of surface and interfacial tension from the maximum pull on a ring. Jour. Amer. Chem. Soc. 52:1751-72.

MaRTin, G.

1928. Chemical engineering. 424 p. (See specifically p. 7.1-8.7.) C. Lockwood and Son, London. 
National Research Council of the United States of America.

1928. International critical tables of numerical data, physics, chemistry, and technology. Vol. 4. $481+4$ p. (See specifically p. 435 and 447.) McGraw-Hill Book Co., New York.

1929. International critical tables of numerical data, physies, chemistry, and technology. Vol. 5. 470 p. (See specifically p. 23.) McGraw-Hill Book Co., New York.

\section{Poiseuille, J. L. M.}

1842. Recherches experimentales sur le mouvement des liquides dans les tubes de très-petits diametres. Compt. Rend. 15:1167-86.

1846. Recherches experimentales sur le mouvement des liquides dans les tubes de très-petits diametres. Mém. Prés. par Divers Savants a l'Acad. Roy. des Scienc. d. l'Inst. de France 9:433-543.

RIDEAL, E. K.

1930. Surface chemistry. 2nd ed. 459 p. (See specifically p. 1-25 and 48-68.) Cambridge (Eng.) University Press.

Siegler, E. H., AND C. H. Popenoe.

1925. Fatty acids as contact insecticides. Jour. Econ. Ent. 18:292-9.

Stamm, A. J.

1928. The structure of soft woods as revealed by dynamic physical methods. Colloid Symposium Monog. 6:83-108.

1932. An electrical conductivity method for determining the effective capillary dimensions of wood. Jour. Phys. Chem. 36:312-25.

TAtTersfield, F., and C. T. Gimingham.

1927. Studies on contact insecticides. Ann. Appl. Biol. 14:331-58.

WASHBURN, E. W.

1921. The dynamies of eapillary flow. Physical Rev. 2nd ser. 17:273-83. 